\title{
Mild dehydration impairs cognitive performance and mood of men
}

\author{
Matthew S. Ganio ${ }^{1,2}$, Lawrence E. Armstrong ${ }^{2 *}$, Douglas J. Casa ${ }^{2}$, Brendon P. McDermott ${ }^{2}$, \\ Elaine C. Lee ${ }^{2}$, Linda M. Yamamoto ${ }^{2}$, Stefania Marzano ${ }^{2}$, Rebecca M. Lopez ${ }^{2}$, Liliana Jimenez ${ }^{3}$, \\ Laurent Le Bellego ${ }^{3}$, Emmanuel Chevillotte ${ }^{3}$ and Harris R. Lieberman ${ }^{4}$ \\ ${ }^{1}$ Texas Health Presbyterian Hospital, Institute for Exercise and Environmental Medicine, Dallas, TX 75231, USA \\ ${ }^{2}$ Human Performance Laboratory, University of Connecticut, Unit 1110, Storrs, CT 06269-1110, USA \\ ${ }^{3}$ Danone Research, RED Waters, Palaiseau 91767 , France \\ ${ }^{4}$ US Army Research Institute of Environmental Medicine, Military Nutrition Division, Natick, MA O1760, USA
}

(Received 6 September 2010 - Revised 17 March 2011 - Accepted 17 March 2011 - First published online 7 June 2011)

\section{Abstract}

The present study assessed the effects of mild dehydration on cognitive performance and mood of young males. A total of twenty-six men (age 20.0 (SD 0.3) years) participated in three randomised, single-blind, repeated-measures trials: exercise-induced dehydration plus a diuretic (DD; $40 \mathrm{mg}$ furosemide); exercise-induced dehydration plus placebo containing no diuretic (DN); exercise while maintaining euhydration plus placebo (EU; control condition). Each trial included three 40 min treadmill walks at $5.6 \mathrm{~km} / \mathrm{h}, 5 \%$ grade in a $27 \cdot 7^{\circ} \mathrm{C}$ environment. A comprehensive computerised six-task cognitive test battery, the profile of mood states questionnaire and the symptom questionnaire (headache, concentration and task difficulty) were administered during each trial. Paired $t$ tests compared the DD and DN trials resulting in $>1 \%$ body mass loss (mean 1.59 (SD $0 \cdot 42) \%$ ) with the volunteer's EU trial (0.01 (SD 0.03) \%). Dehydration degraded specific aspects of cognitive performance: errors increased on visual vigilance $(P=0.048)$ and visual working memory response latency slowed $(P=0.021)$. Fatigue and tension/anxiety increased due to dehydration at rest $(P=0.040$ and 0.029$)$ and fatigue during exercise $(P=0.026)$. Plasma osmolality increased due to dehydration $(P<0 \cdot 001)$ but resting gastrointestinal temperature was not altered $(P=0 \cdot 238)$. In conclusion, mild dehydration without hyperthermia in men induced adverse changes in vigilance and working memory, and increased tension/anxiety and fatigue.

Key words: Vigilance: Reaction time: Reasoning: Memory: Furosemide

The most comprehensive studies that evaluated the effects of dehydration on cognitive performance were conducted more than 20 years ago in laboratories located in a hot climate $^{(1,2)}$. These studies employed a combination of highheat and aerobic exercise to rapidly produce dehydration. Subsequently, at least six other studies have evaluated the influence of body water loss via exercise in the heat ${ }^{(3-5)}$ and suggested that mild dehydration adversely affects cognitive function at approximately $2 \%$ or more body mass loss, but not at $1 \%$ body mass loss ${ }^{(1,2,5)}$. However, because body water loss and hyperthermia (i.e. resulting from exercise in a hot environment) were both present in these studies, the effects of dehydration alone could not be examined. Recently, three studies have examined dehydration without inducing hyperthermia $^{(3,6,7)}$, via passive water restriction or prolonged exercise in a mild environment. These studies induced a narrow range of moderate dehydration $(2 \cdot 6-2 \cdot 8 \%)$ and therefore did not determine whether more modest levels of dehydration affect cognitive function.

The present investigation was designed to assess the effects of mild dehydration, between 1 and $2 \%$ body water loss, on cognitive performance and mood of healthy young males. Few studies have evaluated the effects of such mild dehydration in either men or women ${ }^{(7,8)}$. To isolate mild dehydration as the sole independent variable, body water loss was induced by mild exercise in a mild environment $\left(27 \cdot 7^{\circ} \mathrm{C}\right)$, without hyperthermia. A randomised, repeatedmeasures experimental design was employed. All volunteers participated in two dehydrated and one control condition.

The prior dehydration research discussed above, presumably due to the difficulty in disguising hydrated $v$. dehydrated conditions, was not conducted using double-blind procedures nor was any attempt made to disguise the experimental conditions from investigators or volunteers ${ }^{(9)}$. Therefore, the

Abbreviations: DD, exercise-induced dehydration plus a diuretic; DN, exercise-induced dehydration plus placebo containing no diuretic; EU, euhydration plus placebo.

*Corresponding author: Dr L. E. Armstrong, fax +1 860486 1123, email lawrence.armstrong@uconn.edu 
present study used several procedures to minimise confounding factors, including experimenters' and test subjects' expectation. For example, a diuretic was administered in one of the dehydration conditions, an identical placebo pill in a second dehydrated condition and a placebo in the euhydrated control condition. A diuretic was administered so that it would be difficult for volunteers to distinguish euhydrated from dehydrated trials since in one dehydrated condition, urine output would increase substantially but not in the other. In addition, in all experimental conditions, volunteers were provided with a small volume of water, but the amount administered was disguised by providing the water in opaque containers. All investigators were blind to the experimental treatment except those responsible for monitoring the hydration status of volunteers.

The present study assessed various aspects of cognitive performance, mood and symptoms of dehydration during two mild dehydration sessions and a matched control condition. In addition, physiological variables including heart rate, gastrointestinal and skin temperatures, plasma glucose, lactate, osmolality and cortisol were measured.

\section{Experimental methods}

\section{Subjects}

The present study was conducted according to the guidelines laid down in the Declaration of Helsinki, and all procedures involving human subjects/patients were approved by the University of Connecticut Institutional Review Board for Human Studies. Written informed consent was obtained from all twenty-six men (mean age 20.0 (SD 0.3) years; body mass $79 \cdot 7$ (SD 12.1) kg) before participation. It was estimated that approximately twenty-six volunteers would be needed when calculating sample size using reliability and standard deviation measures from a study with similar cognitive tests ${ }^{(10)}$ and the formula of Cohen ${ }^{(11)}$, with $\alpha$ set at $<0.05$ and power set at 0.8 .

Subjects who consumed an extreme diet, had evidence of disordered eating, were restricting energy intake or had a chronic disease were excluded from participation. The test participants were interviewed to ensure that they were physically fit (i.e. able to complete three $40 \mathrm{~min}$ exercise sessions involving brisk treadmill walking), but not highly trained or sedentary. All subjects spoke English as their primary language.

\section{Experimental design}

In the present cross-over study, subjects participated in $3 \mathrm{~d}$ long laboratory test sessions (08.00-17.50 hours). For each session, subjects were randomised to one of three conditions: exercise-induced dehydration plus a diuretic (DD); exerciseinduced dehydration plus placebo containing no diuretic (DN); euhydration plus placebo (EU). All experiments involved an identical exercise regimen, described below. A third party, not involved in data collection, randomised the test session order. Subjects as well as investigators in the environmental chamber were blinded to the treatment, but an investigator who monitored water administration was not. Sessions were conducted at least $4 \mathrm{~d}$ apart.

\section{Procedures}

To become familiar with study procedures, each subject visited the laboratory for three to five preliminary sessions to practise cognitive tests at rest on a desktop computer and on a notebook computer while walking on a treadmill. When a subject's cognitive performance reached an asymptote on two consecutive days, he was deemed ready to participate in experimental test sessions.

Subjects were instructed regarding adequate fluid intake and sleep before each test session. For this purpose, subjects began each test session in a fully euhydrated state, they consumed $240 \mathrm{ml}$ of supplemental water (i.e. above their usual/ habitual water intake) on each night before testing and $240 \mathrm{ml}$ of water upon waking on the morning of testing. Upon arriving to the laboratory, a urine sample was obtained, and a urine specific gravity of 1.020 confirmed that subjects began each test session in a euhydrated state. Subjects refrained from consuming caffeine and alcohol for $12 \mathrm{~h}$ before each session. Participants performed no exercise of any type (i.e. weightlifting, cycling and running) during the $24 \mathrm{~h}$ before each experiment. Volunteers consumed standard meals, with fluid type and volume specified, for $24 \mathrm{~h}$ before each test session to reduce effects of variation in nutritional intake on outcome variables. Compliance was verified with $24 \mathrm{~h}$ dietary records.

On the morning of each test session, subjects reported to the laboratory at 08.00 or 09.00 hours and consumed one capsule under the supervision of an investigator. Capsules were prepared by a licensed pharmacist (Compounded Solutions in Pharmacy LLC, Monroe, CT, USA), were identical in appearance and contained either a diuretic ( $40 \mathrm{mg}$ furosemide) or placebo. Volunteers reported at two different times so testing could be staggered (times in the following text are for subjects starting at 08.00 hours). After ingesting either the diuretic or placebo, subjects rested quietly in an ante-room adjacent to the testing rooms for $3 \mathrm{~h}$. This allowed time for the diuretic pill to take effect (if that was the assigned trial). During all experiments, subjects were weighed at $15 \mathrm{~min}$ intervals and Volvic Natural Mineral Water ${ }^{\mathrm{rM}}$ (Danone, France) was consumed to replace water loss in urine; the objective was $0 \%$ body weight loss at $3 \mathrm{~h}$ post-pill administration (11.00 hours) independent of trial assignment (i.e. diuretic or placebo); this was done to disguise the experimental conditions by increasing urine flow.

Subjects consumed no food until 10.00 hours when a standardised breakfast was provided; it contained approximately $2929 \mathrm{~kJ}(700 \mathrm{kcal})+174 \mathrm{ml}$ Volvic Natural Mineral Water ${ }^{\mathrm{TM}}$. The water contained the following dissolved substances: $\mathrm{Ca}$, $10 \mathrm{mg} / \mathrm{l} ; \mathrm{Cl}, 8 \mathrm{mg} / \mathrm{l} ; \mathrm{HCO}_{3}^{-}, 65 \mathrm{mg} / \mathrm{l} ; \mathrm{Mg}, 6 \mathrm{mg} / \mathrm{l} ; \mathrm{NO}_{3}, 1 \mathrm{mg} / \mathrm{l}$; $\mathrm{K}, 6 \mathrm{mg} / \mathrm{l}$; silica, $30 \mathrm{mg} / \mathrm{l}$; $\mathrm{Na}, 9 \mathrm{mg} / \mathrm{l} ; \mathrm{SO}_{4}, 7 \mathrm{mg} / \mathrm{l}$. This included $109 \mathrm{mg} / \mathrm{l}$ of total dissolved solids. Immediately after the first (13.50 hours) and second (15.50 hours) cognitive test batteries, subjects also consumed two small food bars as snacks; each feeding contained $879 \mathrm{~kJ}(210 \mathrm{kcal})$ of energy. 
At $11.00,13.00$ and 15.00 hours, subjects entered the environmental chamber and began $40 \mathrm{~min}$ of dehydrating exercise (described below), and then rested for $20 \mathrm{~min}$. Subjects began identical cognitive test batteries at 12.00, 14.00 and 16.00 hours. In the DN and DD trials, subjects consumed no water to replace water loss in urine or sweat during exercise, except for $50 \mathrm{ml}$ after completing the first and second cognitive test batteries, to wet their palates and disguise the experimental condition. Procedures in the EU trial were identical to the DN and DD trials except that fluid lost in urine and sweat was replaced by consuming an equal volume of water during and after each exercise bout. Fluid lost in urine during the test session was assessed by collecting each subject's total urine output. Sweat loss was calculated as the difference in body mass, corrected for urine production and fluid intake. Ambient laboratory environmental conditions were controlled and monitored. In the ante-room outside the environmental chamber, and cognitive testing room, air temperature was maintained at $23^{\circ} \mathrm{C}$.

\section{Exercise dehydration protocol}

Subjects performed $40 \mathrm{~min}$ of treadmill walking $(5.6 \mathrm{~km} / \mathrm{h}, 5 \%$ grade) in a warm environment, to produce body mass loss without inducing hyperthermia. Inside the environmental chamber where the exercise sessions were conducted, air temperature was $27.7 \pm 0.9^{\circ} \mathrm{C}$, the relative humidity was $42 \cdot 0 \pm 12 \cdot 0 \%$ and wind speed provided by a floor fan was $3.5 \mathrm{~m} / \mathrm{s}$. Body mass was measured $( \pm 50 \mathrm{~g}$ ) every $13 \mathrm{~min}$ during exercise when subjects briefly stepped off the treadmill onto a floor scale (model 349KLX; Healthometer, Inc., Alsip, IL, USA). Gastrointestinal temperature was measured every $10 \mathrm{~min}$ of exercise, using an ingestible temperature sensor (CorTemp $^{\text {TM }}$; HQ, Inc., Palmetto, FL, USA). On the morning of each experiment, each participant swallowed the sensor upon arrival to the laboratory. Heart rate was measured every 10 min with a chest cardiotachometer (model S150; Polar Instruments, Inc., Woodbury, NY, USA).

To determine whether dehydration affected perceived exertion or pain during exercise, two self-report scales were administered after $40 \mathrm{~min}$ of exercise: the rating of perceived exertion scale (6- to 20-point scale) for which the extreme options were 'very, very light' and 'very, very hard ${ }^{\text {,(12) }}$, and a perceived leg muscle pain intensity rating ${ }^{(13)}$. The muscle pain scale ranged from 0 ('no pain at all') to 10 ('extremely intense pain, almost unbearable') and offered one unnumbered rating option beyond 10 ('unbearable pain').

To disguise the experimental conditions, subjects were blind to their body mass, urine volume and ingested fluid volume during experiments. This was accomplished by obscuring the body mass scale dial, collecting urine in individual aliquots and removing them from the room before placement in the collection container, and providing drinking water in opaque, covered containers. After every exercise session, subjects left the environmental chamber, moved to a comfortable room $\left(23^{\circ} \mathrm{C}\right.$, dimly lit), dried their skin and hair with a towel, and rested on a chair for $20 \mathrm{~min}$.

\section{Physiological variables at rest}

A urine sample was collected shortly after subjects arrived at the laboratory (08.00 hours) for evaluation of urine specific gravity via a hand-held refractometer. After sitting quietly for $15 \mathrm{~min}$ in a $23^{\circ} \mathrm{C}$ environment, a blood sample was collected. Another blood sample was collected at the completion of each test day (17.00 hours). Change in osmolality from the initial blood samples to the final samples was calculated. Lactate, glucose and cortisol were analysed in the 17.00-hour blood sample. Glucose and lactate were analysed in duplicate using an automated enzymatic technique (YSI 2300 Stat Plus; YSI, Inc., Yellow Springs, OH, USA). Osmolality was measured in duplicate using a freezing-point depression osmometer (model 3250; Advanced Instruments, Inc., Needham Heights, MA, USA). Cortisol was analysed using a competitive cortisol enzyme immunoassay technique (ELISA, DSL-10-2000; Diagnostic Systems Laboratories, Inc., Webster, TX, USA). Immediately preceding the final cognitive test battery, gastrointestinal temperature was recorded at rest (see the previous section).

\section{Cognitive assessment}

Behavioural tasks were selected to assess a broad spectrum of cognitive functions, from relatively simple to complex skills, including vigilance, reaction time, learning, working memory and logical reasoning. Mood states and symptoms were also assessed. Testing was conducted $20 \mathrm{~min}$ after completing each exercise session in a quiet, dimly lit room $\left(23^{\circ} \mathrm{C}\right)$ and took 45-50 min to complete. Computerised tasks (Cognitive Test Software, version 1.2.4; NTT Systems, Inc., North York, ON, Canada) were administered in the same order during each session. An abbreviated test battery was administered when subjects were exercising on the treadmill.

\section{Selection of behavioural tasks}

We selected a battery of cognitive tests designed to assess a wide variety of cognitive functions. This battery assessed basic functions such as choice reaction time and more complex functions including learning, working memory and reasoning, as well as mood state and symptoms of dehydration. Of the tasks, two, matching to sample and repeated acquisition, assess different aspects of working memory. Matching to sample assesses visual working memory and repeated acquisition assesses working memory and motor learning. Prior research, including several studies of dehydration $^{(1,2,7,14)}$, indicates that a wide variety of behavioural parameters can be degraded by moderate to severe dehydration, including learning, working memory and reasoning $^{(1,2)}$, and mood and symptoms ${ }^{(7,15)}$.

The tasks selected are sensitive to a variety of physiological changes in brain function potentially underlying the effects of dehydration on cognitive state. For example, the scanning visual vigilance task is sensitive to changes in adenosinergic and histaminergic function ${ }^{(16,17)}$, and both of these neurotransmitters are associated with fatigue ${ }^{(18,19)}$. Working memory tasks are sensitive to alterations in cholinergic 
function $^{(20)}$. Mood and symptom questionnaires can detect subtle changes in serotonergic function, and it has been suggested that alterations in this neurotransmitter are associated with adverse effects of dehydration on brain function ${ }^{(21)}$.

\section{Cognitive assessment at rest}

Testing at rest was conducted using desktop computer systems running the Windows ${ }^{\circledR}$ operating system. Visual stimuli were presented on $49 \mathrm{~cm}$ (diagonal) liquid crystal display monitors (Acer ${ }^{\circledR}$ model A1716F; Acer ${ }^{\circledR}$ Corp., San Jose, CA, USA). Subjects' responses were input using Razer Tarantula ${ }^{\mathrm{TM}}$ keyboards (model RZ03-00070100-R2U1; Razer ${ }^{\text {TM }}$ Ltd, Carlsbad, CA, USA) which record responses with $1 \mathrm{~ms}$ response latency.

\section{Scanning visual vigilance task}

This test is sensitive to nutritional factors, sleep loss, a variety of environmental conditions, and very low doses of hypnotic drugs and stimulants ${ }^{(16,22)}$. The subject continuously scans a computer screen to detect the occurrence of stimuli that occur on average approximately once per minute and are difficult to detect. The computer records the response time (in ms) and whether or not a stimulus is detected. Responses made before or after stimulus occurrence are recorded as false alarms. The test duration was $40 \mathrm{~min}$. During the preliminary practice sessions, each volunteer's performance was adjusted to a criterion of approximately $60 \%$ correct detections.

Psychomotor vigilance test. This is a test of simple visual reaction time ${ }^{(23)}$. A series of stimuli are presented at random intervals on a screen and the subject must respond as rapidly as possible when a stimulus appears. Parameters include reaction time, false alarms and number of lapses (long duration responses). The test requires subjects to sustain attention and respond to a randomly appearing stimulus on a computer screen by pressing a button. Psychomotor vigilance test performance lapses refer to the instances when a subject fails to respond to the task in a timely manner (i.e. $>500 \mathrm{~ms}$ ). This test required $5 \mathrm{~min}$ to complete.

Four-choice visual reaction time test. Volunteers are presented with a series of visual stimuli at one of four different spatial locations on a computer screen during this 5 min test. They indicate the correct spatial location of each stimulus by pressing one of four adjacent keys on the computer keyboard. Correct responses, incorrect responses, premature errors (responding before the appearance of a stimuli), the response latency for each trial and response latency greater than $1 \mathrm{~s}$ are recorded. Choice reaction time tasks are sensitive to the effects of nutritional factors on cognitive performance ${ }^{(10,24,25)}$.

Matching-to-sample test. To assess short-term spatial memory (working memory) and pattern recognition ${ }^{(10)}$, the volunteer is presented with a matrix of a red and green chequerboard on a colour screen. The matrix appears on the screen for $4 \mathrm{~s}$, and then is removed during a variable delay involving a blank screen. After the delay, two matrices are presented on the screen: the original matrix and a second matrix that differs slightly (i.e. the colour sequence of two of the squares is reversed). The volunteer selects the comparison matrix by touching keys that match the original sample matrix. The task lasts approximately $5 \mathrm{~min}$. If a response is not made within $15 \mathrm{~s}$, a time-out error is recorded. Correct responses and the response time to choose a matrix are also recorded. A response to this task requires a combination of sensory processing, decision-making and a motor response. Therefore, the dependent variable of reaction time includes elements of all of these parameters.

Repeated acquisition test. This test assesses learning and short-term memory ${ }^{(10)}$, and requires approximately $10 \mathrm{~min}$. The volunteer is required to learn, by trial and error, a sequence of twelve key presses on the four arrow keys of a computer. The outline of a rectangle is presented on the screen at the beginning of a trial. Each correct response fills a portion of the rectangle with a solid yellow colour, from left to right. Each incorrect response blanks the screen for $0.5 \mathrm{~s}$. When the screen returns, the volunteer is at the same point in the sequence as before the incorrect response. When a sequence is correctly completed, the rectangle fills, the screen blanks and another empty rectangle reappears for the next trial. A session ends when the volunteer completes fifteen correct sequences (fifteen trials). Each session consists of a new sequence that is randomly selected from a list of thirty-two different sequences. Incorrect responses and time to complete each trial are recorded. A response to this task requires a combination of sensory processing, decisionmaking and a motor response. Therefore, the dependent variable of reaction time includes elements of all of these parameters.

Grammatical reasoning. This $5 \mathrm{~min}$ test assesses languagebased logical reasoning and has been used to assess the effects of various experimental treatments on cognitive function ${ }^{(26)}$. On each trial, either the letter $\mathrm{AB}$ or BA follows a statement. The volunteer decides whether or not each statement correctly describes the order of the two letters. The 'T' key on the keyboard is pressed to indicate that a statement is true, and the ' $F$ ' key is pressed to indicate that a statement is false. A response to this task requires a combination of sensory processing, decision-making and a motor response. Therefore, the dependent variable of reaction time includes elements of all of these parameters.

Profile of mood states questionnaire. The profile of mood states is a widely used, brief, standardised inventory of mood states $^{(27)}$. The volunteers rate a series of sixty-five mood-related adjectives on a 5-point scale, in response to the question, 'How are you feeling right now?' The adjectives factor into six mood sub-scales (tension/anxiety, depression/dejection, anger/hostility, vigour/activity, fatigue/inertia and confusion/ bewilderment). The profile of mood states is sensitive to a wide variety of nutritional manipulations, environmental factors, sleep loss and sub-clinical drug doses ${ }^{(10,16,24,28,29)}$.

Visual analogue rating scales. To complete these scales, the subject placed a pencil mark anywhere along a $100 \mathrm{~mm}$ line between extreme statements at opposite ends of the line. The extreme statements were 'very strong(ly)' and 'not at all strong(ly)'. The questions were, 'How hard was the effort required to complete these tests?' and 'How hard did you have to concentrate to accomplish the tasks successfully?' 
Headache symptoms also were evaluated at the end of each cognitive test session by rating the statement, 'I have a headache'.

\section{Cognitive assessment during exercise}

In addition to cognitive testing at rest, during each treadmill walking session, three tests - the profile of mood states, visual analogue scales and psychomotor vigilance test were administered on a laptop computer (model PCG-5G3L; Sony Corporation of New York, NY, USA) placed on a stationary platform suspended in front of the subject while he walked at the required pace on the treadmill.

\section{Results}

Baseline body mass, hydration status (i.e. urine specific gravity) and self-reported sleep duration for the previous night were assessed when subjects reported to the laboratory each morning. There were no differences $(P>0.05)$ for these three variables when the control (EU) condition was compared with dehydration ( $\geq 1 \%$ ) experiments (Table 1 ). Due to variability in the rate and extent of dehydration over the course of DN and DD test sessions, statistical comparisons for all dependent variables were only conducted when a volunteer attained a level of dehydration $\geq 1 \%$. Such variability was expected since dehydration was induced by moderate exercise in a temperate environment, not by hyperthermia ${ }^{(7)}$.

When level of dehydration (in a DN or DD trial) at the conclusion of any subject's exercise session was $\geq 1.0 \%$, the EU value for the corresponding exercise session was used for comparison with the dehydrated value. After exercise sessions $1-3$, the number of subjects dehydrated $\geq 1 \%$ in DN was 0, 11 and 24, respectively. In the DD trial, 3, 20 and 24 subjects were $\geq 1 \%$ dehydrated after exercise sessions $1-3$. The DN and DD trials that met the $1 \%$ criterion were compared individually with the corresponding EU condition, not averaged together. A criterion of $1 \%$ was established since this is the lowest level of dehydration that has been suggested as capable of altering cognitive function ${ }^{(1,2,9)}$.

Changes in plasma osmolality during the DD and DN experiments that induced $\geq 1 \%$ body mass loss were compared with a paired $t$ test. The increase in osmolality from the

Table 1. Entering hydration and sleep status of male test subjects (Mean values and standard deviations, $n$ 26)

\begin{tabular}{lccccccc}
\hline & \multicolumn{3}{c}{ EU } & & \multicolumn{2}{c}{$\geq 1 \%$} & \\
\cline { 2 - 3 } Physiological variables* & Mean & SD & & Mean & SD & $P$ \\
\hline Body mass $(\mathrm{kg}) \dagger$ & 79.75 & 12.07 & & 79.80 & 12.14 & 0.592 \\
Urine specific gravity $\dagger$ & 1.018 & 0.005 & & 1.019 & 0.007 & 0.291 \\
Hours of sleep $\neq$ & 7.50 & 1.00 & & 7.30 & 0.80 & 0.103 \\
\hline
\end{tabular}

EU, euhydrated (control) condition; $\geq 1 \%$, all trials that involved a body mass loss of $\geq 1 \%$.

* Mean values were not significantly different between the control (EU) and the dehydration ( $\geq 1 \%$ ) trials.

† Upon morning arrival at the laboratory.

$\ddagger$ On the night before testing. beginning to the end of the test day was similar in the DN and DD trials (4 (SD 6) and 7 (SD 6) $\mathrm{mOsm} / \mathrm{kg}$, respectively; $P=0 \cdot 158$ ). Since there was no difference between dehydration induced by the diuretic $v$. water deprivation, whenever either of these treatment conditions resulted in a criterion level of dehydration $(\geq 1 \%)$, the results of all behavioural and physiological parameters assessed were pooled for statistical evaluation. Paired $t$ tests were used to make these comparisons. A $P$ value of $<0.05$ (two-tailed) was the criterion for statistical significance. Post hoc order-effect analysis confirmed that statistical findings were due to the condition and not due to the presentation order of the condition. For the DN and DD sessions that resulted in a $1 \%$ or greater weight loss, mean body mass decreased ( -1.41 (SD 0.27$)$ and -1.73 (SD 0.46) \%, respectively, with an overall decrease of -1.59 (SD 0.42)\%). For EU trials, body weight was stable $(-0.01(\mathrm{SD} 0.03) \%)$; this difference was equivalent to only $5 \mathrm{ml}$ of water in a total body water of $50 \cdot 45$ litres $^{(30)}$.

At rest, dehydration adversely affected two aspects of cognitive performance: false alarms on the scanning visual vigilance task $(P=0.048)$ and response time on the matching-to-sample task $(P=0.021)$. No differences due to dehydration were observed at rest for the psychomotor vigilance test, fourchoice reaction time test, repeated acquisition test or the grammatical reasoning test (Table 2). Mood state was adversely affected by dehydration at rest with tension/anxiety $(P=0.029)$ and fatigue/inertia $(P=0.040)$ increasing. There were no detectable changes in the symptoms of dehydration, headache, inability to concentrate or perceived task difficulty, assessed at rest.

During exercise on the treadmill, one aspect of performance, premature errors on the psychomotor vigilance test, was significantly altered, with the number of premature responses lower at the $1 \%$ or more level of dehydration $(P<0 \cdot 008$; Table 3 ). This small decrease, a total of a mean difference of only 1.3 fewer errors between conditions, does not indicate that dehydration facilitates performance. Premature errors did not decrease when volunteers were tested on the psychomotor vigilance task at rest and no other aspects of this task, such as correct hits or reaction time, were affected by dehydration. In fact, correct hits on the psychomotor vigilance task during exercise decreased due to dehydration, although not significantly $(P=0.059)$, an indication of impaired performance. The mood state of fatigue/inertia was adversely affected by dehydration when volunteers were exercising ( $P=0 \cdot 026$; Table 3$)$, consistent with the finding for this parameter at rest. Symptoms of dehydration (i.e. visual analogue scales, rating of perceived exertion and pain) assessed were not affected by dehydration during treadmill exercise (Table 3 ).

Physiological measurements (Table 4) revealed that postexercise gastrointestinal temperature and post-exercise heart rate were greater $(P=0.001)$ following mild dehydration $(\geq 1 \%)$. The change in plasma osmolality throughout the experimental day (08.00-17.50 hours) was also significantly greater during $>1 \%(5$ ( $\mathrm{sD} 6) \mathrm{mOsm} / \mathrm{kg}$ ) than during $\mathrm{EU}$ (0 ( $\mathrm{sD} 5) \mathrm{mOsm} / \mathrm{kg})$. However, plasma concentrations of lactate, glucose and cortisol were similar during the euhydrated and dehydrated conditions. 
Table 2. Cognitive performance, mood and visual analogue scale ratings, measured at rest in a quiet, dimly lit room

(Mean values and standard deviations)

\begin{tabular}{|c|c|c|c|c|c|}
\hline \multirow{2}{*}{$\begin{array}{l}\text { Cognitive tests and their } \\
\text { components }\end{array}$} & \multicolumn{2}{|c|}{ EU } & \multicolumn{2}{|c|}{$\geq 1 \%$} & \multirow[b]{2}{*}{$P^{*}$} \\
\hline & Mean & SD & Mean & SD & \\
\hline \multicolumn{6}{|l|}{ Scanning visual vigilance } \\
\hline Correct responses & $15 \cdot 40$ & $5 \cdot 80$ & $15 \cdot 10$ & $5 \cdot 60$ & 0.723 \\
\hline Reaction time (s) & 0.93 & 0.21 & 0.98 & $0 \cdot 18$ & 0.073 \\
\hline False alarms & 2.90 & $2 \cdot 20$ & $3 \cdot 70$ & $3 \cdot 20$ & 0.048 \\
\hline \multicolumn{6}{|l|}{ Psychomotor vigilance test } \\
\hline Correct hits & $70 \cdot 70$ & 2.90 & $70 \cdot 40$ & $3 \cdot 10$ & 0.757 \\
\hline Premature errors & 1.90 & 1.60 & 1.70 & 1.80 & 0.377 \\
\hline Reaction time (s) & 0.32 & 0.05 & 0.32 & 0.05 & 0.993 \\
\hline \multicolumn{6}{|l|}{ Four-choice reaction time } \\
\hline Reaction time (ms) & 0.39 & 0.05 & 0.40 & 0.06 & 0.636 \\
\hline Incorrect responses & 3.00 & $3 \cdot 30$ & 3.50 & $2 \cdot 90$ & 0.083 \\
\hline Time-out errors & 0.88 & $3 \cdot 13$ & 0.65 & 2.95 & 0.398 \\
\hline \multicolumn{6}{|l|}{ Matching to sample } \\
\hline Correct responses & $8 \cdot 80$ & 1.90 & 8.90 & 1.80 & 0.625 \\
\hline Time-out errors & 0.60 & 0.80 & 0.60 & 0.80 & 0.818 \\
\hline Response time (s) & 4.24 & 0.66 & 4.42 & 0.71 & 0.021 \\
\hline \multicolumn{6}{|l|}{ Repeated acquisition } \\
\hline Incorrect responses & $18 \cdot 70$ & 3.60 & $19 \cdot 40$ & 4.40 & 0.086 \\
\hline Time to complete (s) & 11.90 & 3.60 & 11.50 & 3.80 & 0.295 \\
\hline \multicolumn{6}{|l|}{ Grammatical reasoning } \\
\hline Correct responses & $29 \cdot 60$ & $2 \cdot 10$ & $29 \cdot 30$ & $2 \cdot 80$ & 0.250 \\
\hline Incorrect responses & 2.40 & $2 \cdot 10$ & $2 \cdot 70$ & $2 \cdot 80$ & 0.250 \\
\hline Response time (s) & 2.95 & 1.03 & $2 \cdot 96$ & 0.97 & 0.383 \\
\hline \multicolumn{6}{|l|}{ Profile of mood states } \\
\hline Tension/anxiety & $8 \cdot 70$ & 3.60 & $9 \cdot 70$ & 4.00 & 0.029 \\
\hline Depression/dejection & $18 \cdot 60$ & $5 \cdot 10$ & $18 \cdot 70$ & 6.00 & 0.917 \\
\hline Anger/hostility & $15 \cdot 60$ & 5.90 & $15 \cdot 30$ & 4.50 & 0.672 \\
\hline Vigour/activity & $-17 \cdot 70$ & 5.90 & -16.90 & 4.70 & 0.282 \\
\hline Fatigue/inertia & $13 \cdot 00$ & $5 \cdot 70$ & 14.50 & $5 \cdot 30$ & 0.040 \\
\hline Confusion/bewilderment & 6.40 & 3.50 & $6 \cdot 80$ & 3.40 & 0.248 \\
\hline Total mood disturbance & 44.60 & $22 \cdot 60$ & $48 \cdot 10$ & 21.00 & 0.164 \\
\hline \multicolumn{6}{|l|}{ Visual analogue scales } \\
\hline Task difficulty & $2 \cdot 20$ & $2 \cdot 10$ & $2 \cdot 30$ & $2 \cdot 10$ & 0.366 \\
\hline Concentration & $2 \cdot 80$ & $2 \cdot 20$ & $2 \cdot 80$ & $2 \cdot 30$ & 0.776 \\
\hline Headache & 0.90 & $1 \cdot 70$ & $1 \cdot 10$ & 2.00 & 0.411 \\
\hline
\end{tabular}

EU, euhydrated (control) condition; $\geq 1 \%$, all trials that involved a body mass loss of $\geq 1 \%$.

${ }^{\star} P$ values reported are the result of paired $t$ tests conducted comparing EU trials with trials achieving dehydration of $\geq 1 \%$.

\section{Discussion}

The present study demonstrates that in men, some adverse effects of dehydration are present at rest and during exercise at a mean level of $-1.59 \%$ dehydration. According to the American College of Sports Medicine ${ }^{(31)}$, this body water loss slightly exceeds euhydration ( $<1 \%$ weight loss), qualifies as mild dehydration and may be encountered routinely by adults during daily activities. In agreement with previous work in this area conducted at somewhat higher levels of dehydration (2-3\%), the effects of mild dehydration on cognitive performance, mood and symptoms of dehydration were limited $^{(3,6,7)}$. Adverse effects on cognitive performance were present at rest and were limited to one aspect of vigilance, false alarms, and one aspect of visual working memory, reaction time. Mood states also were adversely affected by dehydration, with fatigue/inertia significantly increasing both at rest and during exercise, and tension/ anxiety scores elevated at rest, findings that are consistent with the adverse effects observed on cognitive performance
(Table 2). No detectable effects of dehydration were observed in the present study on symptoms that have been associated with more severe levels of dehydration in men, such as headache and self-reported concentration ${ }^{(15)}$. A possible limitation of the present study is the number of statistical comparisons conducted. The statistical approach used in the present study, evaluating each cognitive test and their individual dependent variables separately, is consistent with previous studies using this test battery ${ }^{(14,32)}$ and other test batteries that assess cognitive function in hydration and nutrition research $^{(7,33-36)}$. This statistical approach was employed because different tests assessed different cognitive functions, as described in the Methods section. An analysis aggregating all the cognitive parameters would probably result in different findings. In any case, the limited nature of these effects of mild dehydration on cognitive performance is consistent with studies of other mild and moderate stressors on cognitive performance, mood and symptoms, such as exposure to modest levels of hypobaric hypoxia ${ }^{(37,38)}$ or treatment with drugs 
Table 3. Vigilance, mood, perceptions of performance and symptoms measured during exercise

(Mean values and standard deviations)

\begin{tabular}{|c|c|c|c|c|c|}
\hline \multirow[b]{2}{*}{ Cognitive tests and their components } & \multicolumn{2}{|c|}{ EU } & \multicolumn{2}{|c|}{$\geq 1 \%$} & \multirow[b]{2}{*}{$P^{\star}$} \\
\hline & Mean & SD & Mean & SD & \\
\hline \multicolumn{6}{|l|}{ Psychomotor vigilance test $†$} \\
\hline Correct hits & 71.50 & $2 \cdot 70$ & $72 \cdot 00$ & 1.90 & 0.059 \\
\hline Premature errors & 3.70 & 4.70 & $2 \cdot 40$ & $2 \cdot 60$ & 0.008 \\
\hline Reaction time (s) & 0.30 & 0.04 & 0.29 & 0.04 & 0.702 \\
\hline \multicolumn{6}{|l|}{ Profile of Mood States $\dagger$} \\
\hline Tension/anxiety & $9 \cdot 60$ & $4 \cdot 10$ & $9 \cdot 80$ & 3.80 & 0.481 \\
\hline Depression/dejection & $18 \cdot 40$ & $5 \cdot 60$ & $18 \cdot 50$ & $5 \cdot 70$ & 0.622 \\
\hline Anger/hostility & $15 \cdot 40$ & $6 \cdot 00$ & $15 \cdot 30$ & 5.00 & 0.767 \\
\hline Vigour/activity & $-20 \cdot 00$ & $5 \cdot 20$ & $-19 \cdot 40$ & 5.00 & 0.102 \\
\hline Fatigue/inertia & 13.00 & 4.90 & 13.90 & 4.80 & 0.026 \\
\hline Confusion/bewilderment & $6 \cdot 20$ & $3 \cdot 60$ & $6 \cdot 30$ & $3 \cdot 10$ & 0.654 \\
\hline Total mood disturbance & $42 \cdot 60$ & $22 \cdot 70$ & 44.50 & $20 \cdot 90$ & 0.214 \\
\hline \multicolumn{6}{|l|}{ Visual analogue scales } \\
\hline Task difficulty & $3 \cdot 10$ & $2 \cdot 10$ & $3 \cdot 30$ & $2 \cdot 10$ & 0.503 \\
\hline Concentration & $3 \cdot 80$ & $2 \cdot 40$ & $4 \cdot 10$ & $2 \cdot 20$ & 0.241 \\
\hline Headache & $1 \cdot 10$ & 1.90 & $1 \cdot 10$ & 1.90 & 0.481 \\
\hline RPE & 9.60 & $2 \cdot 30$ & 9.40 & 1.80 & 0.286 \\
\hline Pain rating & 0.80 & 0.80 & 0.80 & 0.70 & 0.610 \\
\hline
\end{tabular}

such as mild hypnotics ${ }^{(16)}$, which have modest effects on cognitive performance.

The brain mechanisms responsible for the deterioration of cognitive performance and mood resulting from mild dehydration are not known. Changes in electrolyte balance may directly affect higher-order brain regions since precise regulation of electrolyte balance is essential for chemical and electrical neurotransmission. Alternatively, hypothalamic neurons that detect dehydration may signal higher-order cortical brain regions when the initial physiological indicators of dehydration appear ${ }^{(39)}$. Hypothalamic serotonergic function appears to be altered due to dehydration and consequently this neurotransmitter, which is critical for regulation of key aspects of behaviour, may mediate the effects of dehydration $^{(21)}$.
The findings of the present study, conducted with male volunteers, can be compared with the results of a similar study of females $^{(8)}$. At an almost identical level of dehydration $(1.39 \%$ body weight loss), resulting from the same exercise regimen and conducted in the same laboratory environment, cognitive performance of females was not substantially altered. Identical performance, mood and symptom tests and questionnaires were used in both studies. Although the extent of cognitive performance decrements in females was somewhat less than those observed in males, adverse changes in mood and symptoms were substantially greater in females than in males, both at rest and during exercise. In addition to adverse changes in fatigue/inertia and tension/anxiety observed in males, confusion/bewilderment, vigour/activity and total mood disturbance also deteriorated both at rest and during exercise

Table 4. Gastrointestinal temperature ( $\left.T_{\mathrm{gi}}\right)$, heart rate and plasma constituents, at the end of exercise and at rest

(Mean values and standard deviations)

\begin{tabular}{|c|c|c|c|c|c|}
\hline \multirow[b]{2}{*}{ Physiological measurements } & \multicolumn{2}{|c|}{ EU } & \multicolumn{2}{|c|}{$\geq 1 \%$} & \multirow[b]{2}{*}{$P$} \\
\hline & Mean & SD & Mean & SD & \\
\hline Post-exercise $T_{\mathrm{gi}}\left({ }^{\circ} \mathrm{C}\right)^{\star}$ & 37.55 & 0.42 & $37 \cdot 71$ & 0.36 & 0.005 \\
\hline Post-exercise heart rate (beats $/ \mathrm{min})^{*}$ & $127 \cdot 00$ & 14.00 & 132.00 & 14.00 & 0.001 \\
\hline Resting $T_{\mathrm{gi}}\left({ }^{\circ} \mathrm{C}\right) \dagger$ & 37.46 & 0.82 & 37.61 & 0.67 & 0.238 \\
\hline Resting plasma osmolality change $(\mathrm{mmol} / \mathrm{kg}) \ddagger$ & 0.00 & $5 \cdot 00$ & $5 \cdot 00$ & $6 \cdot 00$ & $<0.001$ \\
\hline Resting plasma lactate $(\mathrm{mmol} / \mathrm{l}) \ddagger$ & 1.00 & 0.50 & $1 \cdot 10$ & $0 \cdot 80$ & 0.287 \\
\hline Resting plasma glucose (mg/l)‡ & $45 \cdot 6$ & $1 \cdot 7$ & $46 \cdot 4$ & $2 \cdot 5$ & 0.055 \\
\hline Resting plasma cortisol $(\mathrm{ng} / \mathrm{ml}) \ddagger$ & $27 \cdot 10$ & $12 \cdot 50$ & $29 \cdot 70$ & $8 \cdot 10$ & 0.086 \\
\hline
\end{tabular}

EU, euhydrated (control) condition; $\geq 1 \%$, all trials that involved a body mass loss of $\geq 1 \%$.

${ }^{*}$ At the end of the third $40 \mathrm{~min}$ exercise bout $\left(27 \cdot 6^{\circ} \mathrm{C}\right.$ air temperature).

$\dagger$ At rest, immediately before cognitive test administration $\left(23^{\circ} \mathrm{C}\right.$ air temperature).

$\ddagger$ At rest, immediately after cognitive test administration $\left(23^{\circ} \mathrm{C}\right.$ air temperature). 
in females. Furthermore, symptoms of dehydration such as headache, concentration and task difficulty were present at rest and during exercise in females at a mean level of dehydration of $1.39 \%$ body weight loss.

These sex differences may be attributable to differences in the aerobic capacity of the males and females who participated, as treadmill speeds and duration were identical in both studies. Because females had a lower maximal aerobic power than males, consistent with differences in the general US population ${ }^{(40)}$, they exercised at a higher percentage of their maximal aerobic capacity. Consistent with this interpretation, the resting post-exercise heart rate of males, whether in the dehydrated or euhydrated conditions, was lower than females' heart rates and the rectal temperatures of males increased less at nearly identical levels of dehydration ${ }^{(8)}$. Furthermore, unlike males, rating of perceived exertion and perception of pain in females during exercise significantly increased as a result of dehydration ${ }^{(8)}$. Thus, it appears likely that these sex differences were due to differences in fitness between men and women not due to sex differences in susceptibility to the adverse effects of dehydration. Since males and females in the general population substantially differ in levels of aerobic fitness, the findings of the present study are applicable to the general population ${ }^{(40)}$. However, to determine the underlying cause of sex differences in sensitivity to dehydration, dehydration studies should be conducted with males and females selected to have similar levels of aerobic fitness.

In conclusion, in males, acute dehydration of $1.59 \%$ body weight loss, induced without causing hyperthermia, had limited but detectable effects on certain aspects of cognitive performance, specifically vigilance and working memory, and results in adverse changes in mood states of fatigue and anxiety that are typically associated with adverse changes in cognitive performance in a variety of circumstances $^{(10,16,24,25,38)}$. This conclusion is supported by results from a similar study conducted with females at a similar level of dehydration (1.39\% body weight loss), which resulted in little change in cognitive performance, but substantial adverse changes in mood and symptoms. Both sexes experienced adverse, but somewhat different, behavioural effects of dehydration below $2 \%$ body weight loss ${ }^{(8)}$. Such modest loss in body weight can occur in everyday activities ${ }^{(41)}$, demonstrating the importance of maintaining optimal hydration. Furthermore, since females appear to be more susceptible to the effects of mild dehydration than males, probably because they are on average less aerobically fit, maintaining optimal hydration may be particularly critical when they participate in aerobic activities ${ }^{(8)}$. In addition, individuals with medical conditions that increase susceptibility to dehydration such as diabetics, as well as children and elderly individuals, may be more likely to experience adverse behavioural effects of mild dehydration.

\section{Acknowledgements}

The present study was supported by Danone Research, Palaiseau, France. The authors' contributions were as follows:
L. E. A., D. J. C., L. J., L. L. B., E. C. and H. R. L. contributed to the study design; M. S. G., L. E. A., D. J. C., E. C. L., B. P. M., L. M. Y., S. M. and R. M. L. helped in data collection; M. S. G., L. E. A., E. C. L., S. M. and H. R. L. performed the data analysis; L. E. A., M. S. G. and H. R. L. were involved in writing of the manuscript; M. S. G., L. E. A., D. J. C., E. C. L., B. P. M., L. M. Y., S. M., R. M. L., L. J., L. L. B., E. C. and H. R. L. helped in editorial review of the manuscript. L. E. A. is a Danone Research Scientific Advisory Board member, paid consultant. L. J., L. L. B. and E. C. are employed by Danone Research. H. R. L. is currently a consultant to Danone Waters Research \& Development but was not compensated by them for this project. M. S. G., D. J. C., E. C. L., B. P. M., L. M. Y., S. M., R. M. L. and H. R. L. declare no conflict of interest. The authors thank Dr Matthew Kramer for statistical assistance, and Lauren A. Thompson for technical assistance with manuscript revision and submission. The views, opinions and/or findings of the present study are those of the authors, and should not be construed as an official Department of the Army position, policy or decision, unless so designated by other official documentation. Citation of commercial organisation and trade names in the present study does not constitute an official Department of the Army endorsement or approval of the products or services of these organisations. Present affiliations are: B. P. M., Department of Health and Human Performance, University of Tennessee, Chattanooga, TN, USA; E. C. L., Mount Desert Island Biological Laboratory, Salisbury Cove, ME, USA; R. M. L., Department of Orthopaedics and Sports Medicine, University of South Florida, Tampa, USA.

\section{References}

1. Sharma VM, Sridharan K, Pichan G, et al. (1986) Influence of heat-stress induced dehydration on mental functions. Ergonomics 29, 791-799.

2. Gopinathan PM, Pichan G \& Sharma VM (1988) Role of dehydration in heat stress-induced variations in mental performance. Arch Environ Health 43, 15-17.

3. Cian C, Barraud PA, Melin B, et al. (2001) Effects of fluid ingestion on cognitive function after heat stress or exercise-induced dehydration. Int J Psychophysiol 42, 243-251.

4. Baker LB, Conroy DE \& Kenney WL (2007) Dehydration impairs vigilance-related attention in male basketball players. Med Sci Sports Exerc 39, 976-983.

5. Tomporowski PD, Beasman K, Ganio MS, et al. (2007) Effects of dehydration and fluid ingestion on cognition. Int J Sports Med 28, 891-896.

6. Cian C, Koulmann N, Barraud PA, et al. (2000) Influence of variations in body hydration on cognitive function: effect of hyperhydration, heat stress, and exercise-induced dehydration. J Psychophysiol 14, 29-36.

7. Szinnai G, Schachinger H, Arnaud MJ, et al. (2005) Effect of water deprivation on cognitive-motor performance in healthy men and women. Am J Physiol Regul Integr Comp Physiol 289, R275-R280.

8. Armstrong LE, Ganio MS, Lee E, et al. (2010) Mild dehydration degrades mood and symptoms, not cognitive performance in females: a placebo-controlled study. FASEB $J$ 24, 991.7 (abstract). 
9. Lieberman HR (2007) Hydration and cognition: a critical review and recommendations for future research. $J \mathrm{Am}$ Coll Nutr 26, 555S-561S.

10. Lieberman HR, Tharion WJ, Shukitt-Hale B, et al. (2002) Effects of caffeine, sleep loss, and stress on cognitive performance and mood during U.S. Navy SEAL training. Psychopharmacology (Berl) 164, 250-261.

11. Cohen J (1969) Statistical Power Analysis for the Behavioral Sciences. New York: Academic Press.

12. Borg G (1970) Perceived exertion as an indicator of somatic stress. Scand J Rehabil Med 2, 92-98.

13. Cook DB, O'Connor PJ, Eubanks SA, et al. (1997) Naturally occurring muscle pain during exercise: assessment and experimental evidence. Med Sci Sports Exerc 29, 999-1012.

14. Lieberman HR, Bathalon GP, Falco CM, et al. (2005) Severe decrements in cognition function and mood induced by sleep-loss, heat, dehydration and undernutrition during simulated combat. Biol Psychiatry 57, 422-429.

15. Shirreffs SM, Merson SJ, Fraser SM, et al. (2004) The effects of fluid restriction on hydration status and subjective feelings in man. Br J Nutr 91, 951-958.

16. Fine BJ, Kobrick JL, Lieberman HR, et al. (1994) Effects of caffeine or diphenhydramine on visual vigilance. Psychopharmacology (Berl) 114, 233-238.

17. Olson CA, Thornton JA, Adam GE, et al. (2010) Effects of two adenosine antagonists, quercetin and caffeine, on vigilance and mood. J Clin Psychopharmacol 30, 573-578.

18. Fredholm BB, Battig K, Holmen J, et al. (1999) Actions of caffeine in the brain with special reference to factors that contribute to its widespread use. Pharmacol Rev 51, 83-133.

19. Miller DB \& O'Callaghan JP (2006) The pharmacology of wakefulness. Metabolism 55, S13-S19.

20. Ellis KA \& Nathan PJ (2001) The pharmacology of human working memory. Int J Neuropsychopharmacol 4, 299-313.

21. Popova NK, Ivanova LN, Amstislavskaya TG, et al. (2001) Brain serotonin metabolism during water deprivation and hydration in rats. Neurosci Behav Physiol 31, 327-332.

22. Lieberman HR, Coffey BP \& Kobrick J (1998) A vigilance task sensitive to the effects of stimulants, hypnotics and environmental stress - The Scanning Visual Vigilance Test. Behav Res Methods Instrum Comput 30, 416-422.

23. Dinges DF \& Powell JW (1985) Microcomputer analyses of performance on a portable, simple, visual RT task during sustained operations. Behav Res Methods Instrum Comput 17, 652-655.

24. Shukitt-Hale B, Askew EW \& Lieberman HR (1997) Effects of 30 days of undernutrition on reaction time, moods, and symptoms. Physiol Behav 62, 783-789.

25. Lieberman HR, Bathalon GP, Fulco CM, et al. (2005) The fog of war: decrements in cognitive performance and mood associated with combat-like stress. Aviat Space Environ Med 76, C7-C14.

26. Baddeley AD (1968) A 3 min reasoning test based on grammatical transformation. Psychon Sci 10, 341-342.
27. McNair DM, Lorr M \& Droppelman LF (1971) Manual for the Profile of Mood States. San Diego, CA: Educational and Industrial Testing Service.

28. Banderet LE \& Lieberman HR (1989) Treatment with tyrosine, a neurotransmitter precursor, reduces environmental stress in humans. Brain Res Bull 22, 759-762.

29. Lieberman HR, Falco CM \& Slade SS (2002) Carbohydrate administration during a day of sustained aerobic activity improves vigilance, as assessed by a novel ambulatory monitoring device, and mood. Am J Clin Nutr 76, 120-127.

30. Armstrong LE, Kenefick RW, Castellani JW, et al. (1997) Bioimpedance spectroscopy technique: intra-, extracellular, and total body water. Med Sci Sports Exerc 29, 1657-1663.

31. American College of Sports Medicine, Sawka MN, Burke LM, et al. (2007) American College of Sports Medicine position stand. Exercise and fluid replacement. Med Sci Sports Exerc 39, 377-390.

32. Lieberman HR, Caruso CM, Niro PJ, et al. (2008) Severe decrements in cognition function and mood induced by sleep-loss, heat, dehydration and undernutrition during simulated combat. Biol Psychiatry 57, 422-429.

33. Crews WD Jr, Harrison DW \& Wright JW (2008) A doubleblind, placebo-controlled, randomized trial of the effects of dark chocolate and cocoa on variables associated with neuropsychological functioning and cardiovascular health: clinical findings from a sample of healthy, cognitively intact older adults. Am J Clin Nutr 87, 872-880.

34. Gordon RC, Rose MC, Skeaff SA, et al. (2009) Iodine supplementation improves cognition in mildly iodine-deficient children. Am J Clin Nutr 90, 1264-1271.

35. Benton D \& Donohoe R (2011) The influence of creatine supplementation on the cognitive functioning of vegetarians and omnivores. BrJ Nutr 105, 1100-1105.

36. D'Anci KE, Vibhakar A, Kanter JH, et al. (2009) Voluntary dehydration and cognitive performance in trained college athletes. Percept Mot Skills 109, 251-269.

37. Shukitt-Hale B, Stillman MJ, Marlowe BE, et al. (1994) Hypobaric hypoxia impairs spatial memory in an exposuredependent fashion. Behav Neural Biol 62, 244-252.

38. Shukitt-Hale B, Banderet LE \& Lieberman HR (1998) Elevation-dependent symptom, mood, and performance changes produced by exposure to hypobaric hypoxia. Int J Aviat Psychol 8, 319-334.

39. Di S \& Tasker JG (2004) Dehydration-induced synaptic plasticity in magnocellular neurons of the hypothalamic supraoptic nucleus. Endocrinology 145, 5141-5149.

40. Wang CY, Haskell WL, Farrell SW, et al. (2010) Cardiorespiratory fitness levels among US adults 20-49 years of age: findings from the 1999-2004 National Health and Nutrition Examination Survey. Am J Epidemiol 171, 426-435.

41. Sawka MN, Cheuvront SN \& Carter R (2005) Human water needs. Nutr Rev 63, S30-S39. 